\title{
REVIT DYNAMO: DESIGNING OBJECTS OF COMPLEX FORMS. TOOLKIT AND PROCESS AUTOMATION FEATURES
}

\author{
Daria Shishina ${ }^{1}$, Philipp Sergeev ${ }^{2}$ \\ $1,2 \mathrm{OOO}$ "INPI" \\ 2 Yamskogo polya 3-ya, Moscow, Russia, 125040 \\ ${ }^{2}$ Corresponding author: sergeev@i-npi.ru
}

\section{Abstract}

Introduction: Design of objects of complex forms (non-linear, round, dynamic in their geometry) currently causes difficulties in the construction of geometry and documentation of various project stages. In this paper, proven approaches towards modeling objects of complex forms are presented. Here, the authors mean forms that represent planes bent in three directions, which shall be built according to the rules of the graphical display of drawings. Methods: A toolkit of the Autodesk Revit software (Masses, Model In-Place) is considered together with an additional script created using a visual-programming add-on - Dynamo. The authors formulate approaches to work with complex geometry in Revit that make it possible to model objects of complex forms correctly. Examples of using standard program tools in unusual application logic are given. Since standard tools have limited functionality, it is shown how to use a Dynamo-based script that automates and speeds up the process of creating geometric forms. Results and discussion: Optimization of work with non-standard instances of the project geometry is performed, and a subsequent paradigm for the design of non-standard construction objects is formulated.

\author{
Keywords \\ Masses, Model In-Place, automation, complexity of forms, adaptability
}

\section{Introduction}

Architecture and structural elements are shifting away from simple linear forms. Such tendency is apparent in the modern construction sector. More and more emphasis is put on generative design, mathematical modeling of facades, analytical description of structures. All these approaches have an important common idea - a transition from structures of simple form, which are easy to design, present graphically, and manufacture, to structures, forms of which are determined not by simplicity but by content.
Requirements for modern buildings become more advanced, the economy forces designers to develop structures with the minimum material consumption but with the maximum areas. Previously, only great architects who had plenty of time and money could do that (Figures 1, 2). Such a situation in the construction market dictates its rules, thus creating progress in design and, in particular, the growing development of BIM technologies (Garber, 2014).

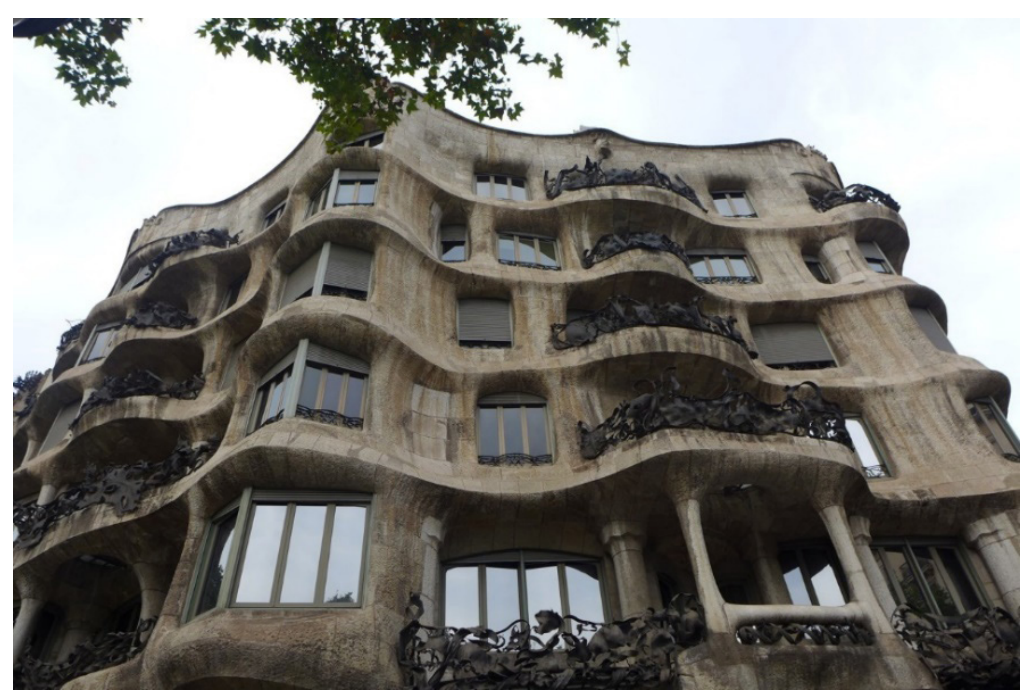

Figure 1. Mila House (Casa Mila). Architect: Antoni Gaudi i Cornet 


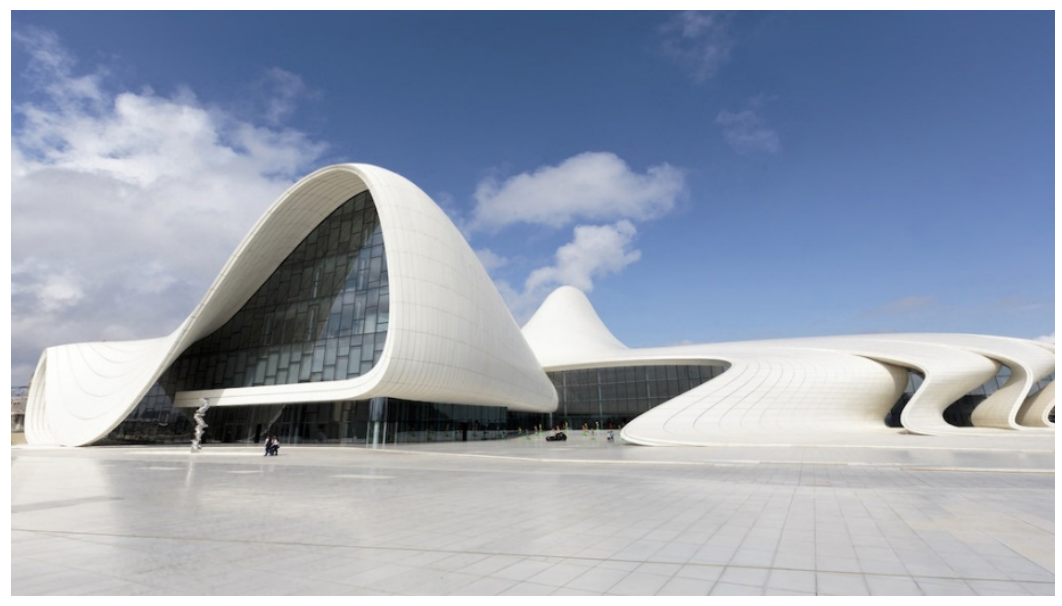

Figure 2. Heydar Aliyev Center building. Architect: Zaha Mohammad Hadid

When using the information modeling technology, it is required to build processes of creating elements of complex and information-rich forms, as that is the major problem of the designer.

When analyzing difficulties at the beginning of object design, it is necessary to answer the following questions:

1) What stages of documentation are covered by the design of the object? It is required to establish levels of detail $(L O D / L O I)$ (The American Institute of Architects, 2019).

2) Based on the principles of the concept (in particular, the purpose of the building, its approximate volumes, and general style), it is required to identify the most complex regions that will require the most time for elaboration.

3 ) Is the general logic of modeling the most complex regions elaborated (monolithic structures, dynamically modifiable facade structures, etc.)?

4) Is it needed to adapt templates to the current requirements, adding means of automation?
Therefore, the formation of model requirements represents an important stage of process planning. Approaches towards modeling and enriching elements with information will depend on those requirements. The requirements shall be analyzed at the very beginning of works to avoid altering large blocks of geometry at the detailed documentation stage (Kensek, Noble, 2014).

Methods of working with complex geometry in Autodesk Revit are described below. The basic tools are Masses and Model In-Place, which are the main replacement for system families in case of constructing complex geometry. Since standard tools have limited functionality, a Dynamo-based script is implemented, which automates and speeds up the process of form creation. In turn, these forms serve as the basis for the positioning of several categories of elements: subsystems of facades, monolithic structures, finishes of stairs.

Masses. They are located on the Massing and Site panel in Revit (Figure 3).

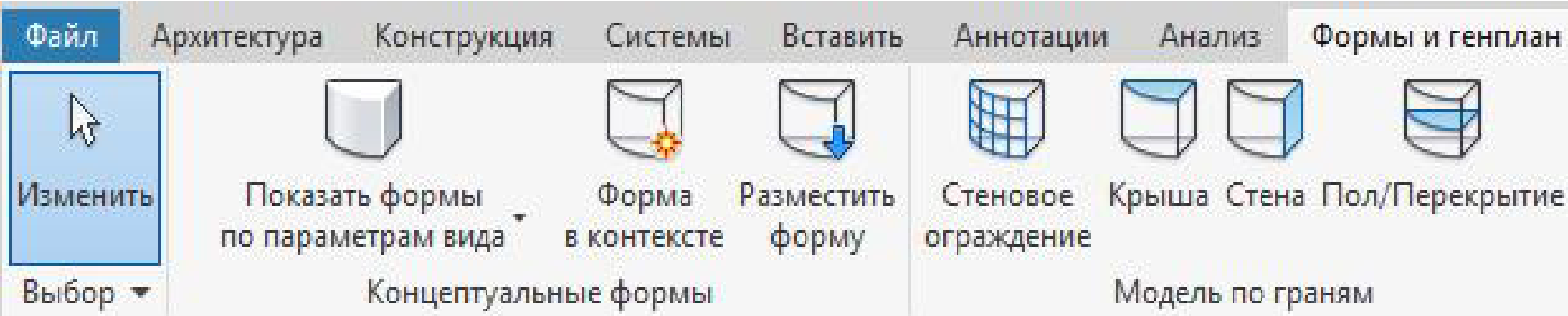

Figure 3. Location on the Revit ribbon

Let us consider three main applications of Masses in the design of objects:

1. Masses as a tool of conceptual design.

2. A basic tool when designing "complex" architectural forms.

3. A tool of automation using visual programming.

There is a lot of guidelines on the construction of forms for conceptual design, which describe methods of work at the conceptual design stage in detail (Vandezande, Krygiel, Read, 2013; Read, Krygiel, Vandezande, 2011; Lantsov, 2014).

For instance, in residential construction, which currently occupies a very large niche in the construction business, forms are often used in conceptual design for the extraction of certain volumes. 
Mass Floor Schedules contain information on the following mass characteristics: Floor Volume, Floor Perimeter, Exterior Surface Area with account for the Level, Floor Area. Using calculation formulae, it is also possible to derive Floor Area (S_floor) percentage of the total Floor Area ( $S$ total) and Exterior Surface Area (S_exterior surface) percentage of the total Exterior
Surface Area (S_total surface) of a building (Figure 4). Using a standard tool to calculate energy performance of a building through the forms, it is possible to derive and calculate total facade glazing percentage (Figure 5) and approximate energy performance (it should be noted that Revit uses data of ASHRAE tables) (Shariq, 2010).

<В_формообразующих элемент ов-перекрып чūх

\begin{tabular}{|c|c|c|c|c|c|c|}
\hline B & $\mathrm{C}$ & D & $E$ & $F$ & G & $\mathrm{H}$ \\
\hline 0бьем $\exists$ maжa & Периметр эmaжа & S наружной noBepxноcmu & Площадь эпажа & Чровень & $\%$ S 3 m om Soסщ & $\%$ SHap noB-mu om Soסщ \\
\hline 2645,39 & 200531 & 701,9 & 755,8 & AP_01 3ma\%_0.000 & $10 \%$ & $10 \%$ \\
\hline 2645,39 & 200531 & 701,9 & 755,8 & AP_02 3 maw_+ 3.500 & $10 \%$ & $10 \%$ \\
\hline 2645,39 & 200531 & 701,9 & 755,8 & AP_03 3max_+7.000 & $10 \%$ & $10 \%$ \\
\hline 2645,39 & 200531 & 701,9 & 755,8 & AP_04 3max_+10.500 & $10 \%$ & $10 \%$ \\
\hline 2645,39 & 200531 & 701,9 & 755,8 & AP_05 3max_+14.000 & $10 \%$ & $10 \%$ \\
\hline 2645,39 & 200531 & 701,9 & 755,8 & AP_06 3max_+17.500 & $10 \%$ & $10 \%$ \\
\hline 2645,39 & 200531 & 701,9 & 755,8 & AP_07 $3 \mathrm{max}_{-}+21000$ & $10 \%$ & $10 \%$ \\
\hline 1637,39 & 200531 & 797,9 & 755,8 & AP_08 $3 \mathrm{max} \_+24.500$ & $10 \%$ & $11 \%$ \\
\hline 1188,89 & 120531 & 524,9 & 419,8 & AP_09 $3 \mathrm{ma} \_+28.000$ & $6 \%$ & $7 \%$ \\
\hline 814,89 & 64531 & 225,9 & 232,8 & AP_10 3max_+31500 & $3 \%$ & $3 \%$ \\
\hline 814,89 & 64531 & 225,9 & 232,8 & AP_11 3 max $\_+35.000$ & $3 \%$ & $3 \%$ \\
\hline 349,24 & 64531 & 329,6 & 232,8 & AP_12 Эmax_+38.500 & $3 \%$ & $5 \%$ \\
\hline 23323,02 & 1918367 & 7017,0 & 7164,9 & & $100 \%$ & $100 \%$ \\
\hline 23323,02 & 1918367 & 7017,0 & 7164,9 & & $100 \%$ & $100 \%$ \\
\hline
\end{tabular}

Figure 4. Mass Floor Schedule

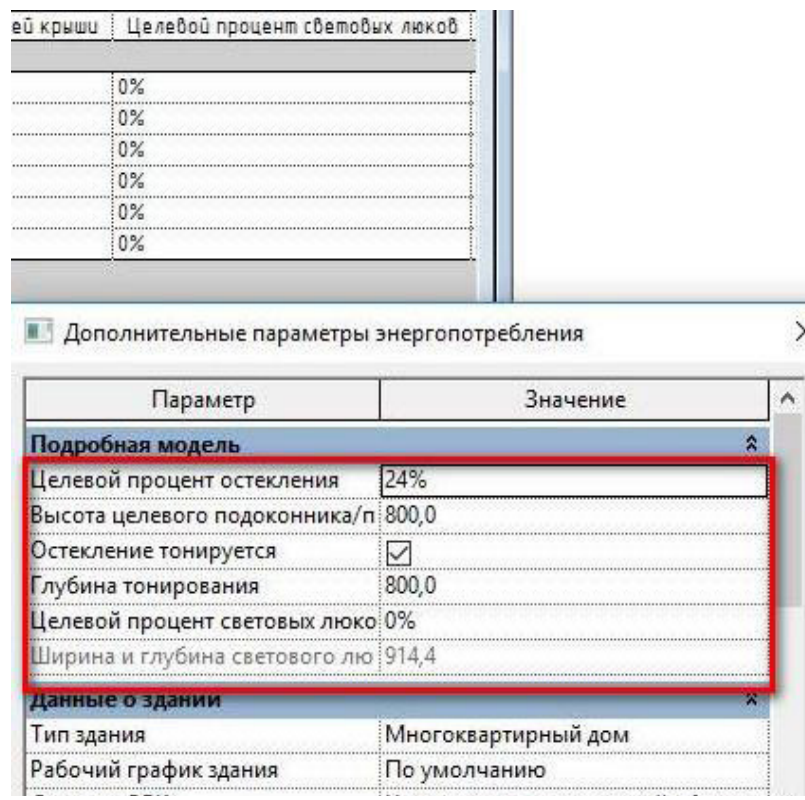
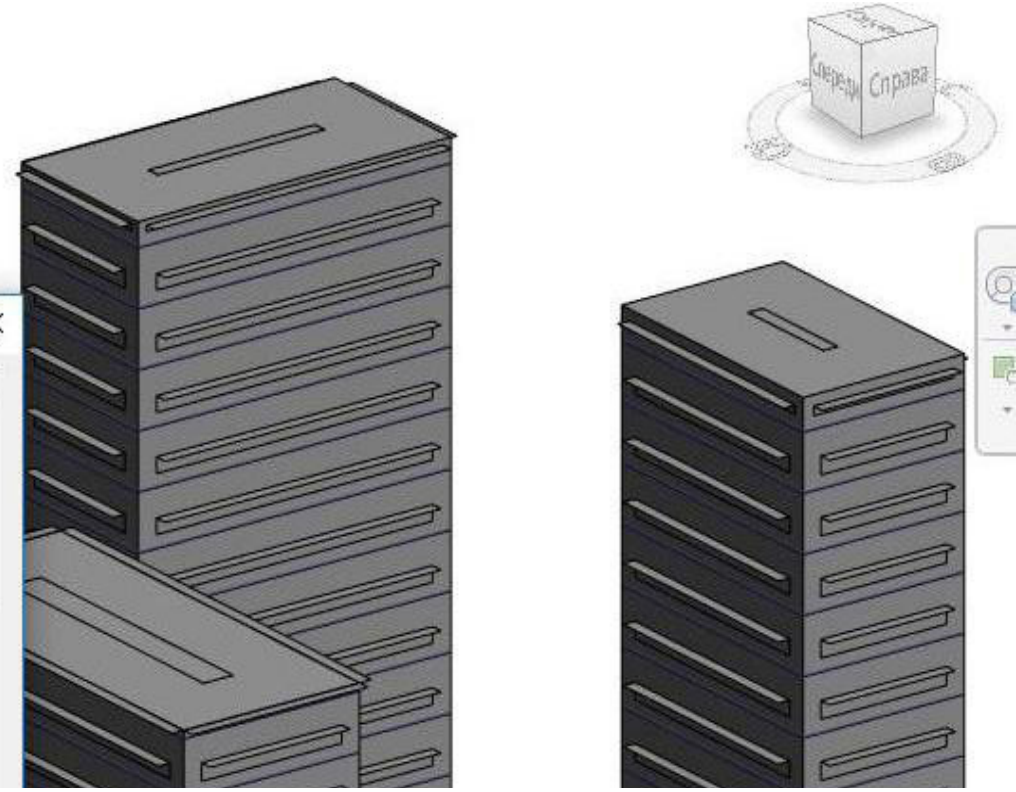

Figure 5. Masses when creating an Energy Model

There are ways to introduce basic requirements of standardizing documents and basic calculation formulae through the Dynamo add-in or calculation formulae in schedules, and also use the interaction of the Autodesk Revit, MS Project, and Excel toolkits to calculate energy consumption at the stage of conceptual design. The process is based on the integration of data from Autodesk Revit into MS Project (Oolacay, 2015).
It is possible to integrate Dynamo in the Revit environment. Dynamo is an open-source add-in for Revit. Such functionality allows us to create masses with the help of visual programming. There is a lot of such examples in design, and the logic of scripts is based on customer's requirements (Mogilina, 2018; Poddorogina, 2018; Vandezande, Krygiel, Read, 2013). 
Capabilities of such toolkit have many advantages for developers (e.g. obtaining initial data items required for construction). Variability of its use makes it possible to compile a catalog of existing layouts used by the developer, thus standardizing its approach to the site development, getting an idea of the future of the object at the conceptual design stage. Company specialty determines the use of various approaches to the creation of mass families (Krygiel, Nies, McDowell, 2008).

But this way of using forms is not a major one. If forms are viewed as the basis for the construction of various elements within the project, then, normally, the following categories are used:

A. Monolithic structures (ramps, passages, tunnels, structures bending in three planes).

B. Complex parametric facades (shells, exterior glazing grids with different in-fills, bionics).

C. Stairs and railings.

Monolithic structures. When designing monolithic structures of diverse complexity, it is important to consider basic documentation requirements. For example, plans and section views shall have uniform graphics without additional separators (Figure 6). Such graphics shall be suitable for future use by designers (if we take into account the copying of elements from the architect's model).
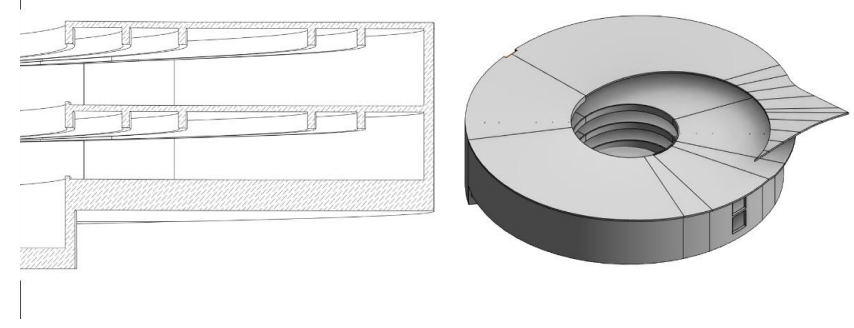

Figure 6. Example of the parking ramp section view

While no difficulties generally arise if straight objects are drawn, when designing objects of non-standard forms, it is required to shift away from using system tools of modeling and utilize the Model In-Place tool or masses. As for the parking ramp presented above, Model In-Place was applied, or more specifically, the Swept Blend tool, using profiles describing the start and end levels of the structure. It is impossible to model the structure using system tools in such a way as to display it correctly in section views and ensure that it is geometrically correct in general (Figures 7, 8).

A separate collection of materials covering design using the Model In-Place tool can be developed as it is important to know about its features and capabilities to ensure its beneficial use. Its main function is to replace system tools. When drawing of a complex geometry element is planned and a tool is selected, according to the initial data, it is necessary to bear in mind the following:

a. Elements created in the Model In-Place space that have a single path, coinciding in one of the faces, cannot be joined together. b. Elements, the area of which is to be accounted for in a schedule, shall be made in one layer in the space of one Model In-Place, or, depending on the number of layers, the corresponding formula shall be introduced to the schedule.

c. To avoid mistakes, Model In-Place void forms, cutting through system elements, need to cut only one appropriate element.

d. A void form cannot cut through a solid if faces of their sketches coincide.

When applying a certain logic of building elements, it is necessary to bear in mind the processes of automation and exchange of information between adjacent structures, existing in your company. It should also be remembered that many scripts centered around a certain logic of interaction between elements may fail to work with the elements, which were modeled not according to the logic of reading information from automation tools. In such cases, it is better to convert scripts and plugins, transforming the conditions and logic of action within the add-in, to avoid execution of the object on a case-by-case basis.

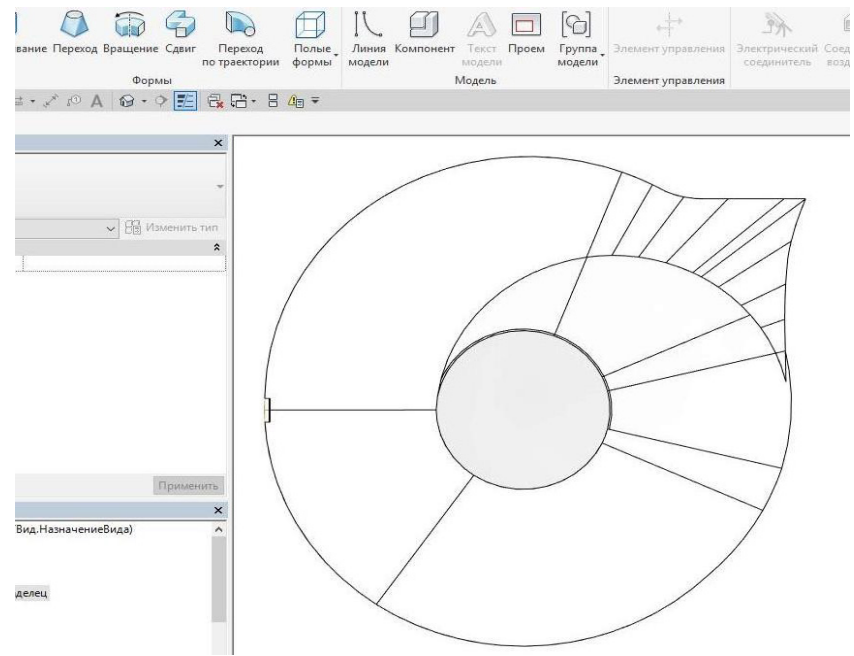

Figure 7. Plan view of the parking ramp when using the Swept Blend tool

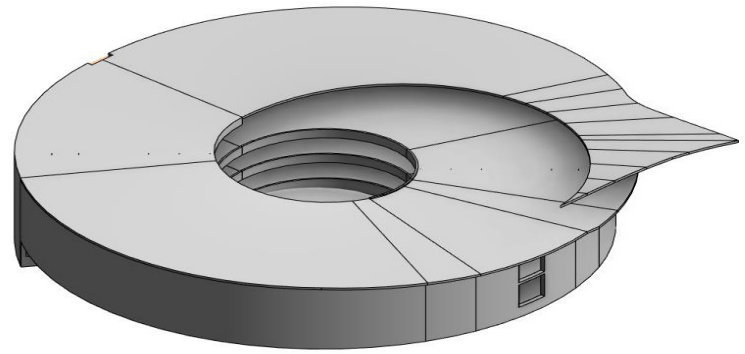

Figure 8. 3D view of the parking ramp when using the Swept Blend tool

Similar curved structures can also be built using forms. The same form can serve as the basis both for monolithic walls and for the facade subsystem structure (Figures 9 , 10, 11). 


\section{Architecture and Engineering Volume 4 Issue 3}

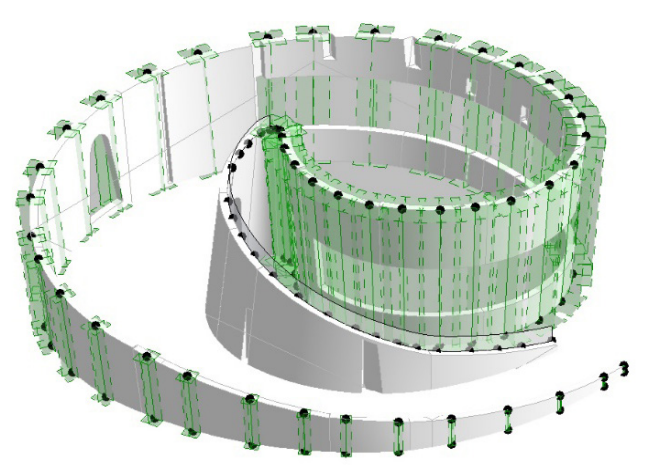

Figure 9. Form sketching process (1)

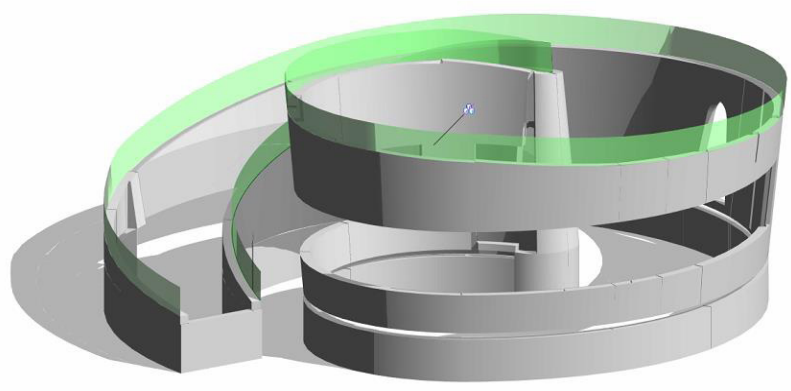

Figure 10. Form sketching process (2)

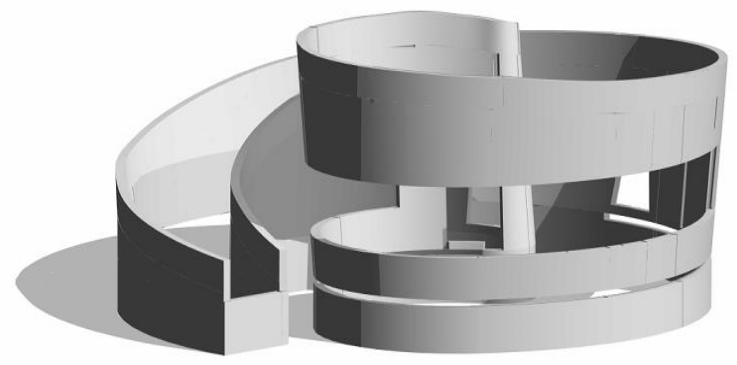

Figure 11. Form-driven monolith

In this object, the walls at each point have a certain slope and a certain height relative to the plane of the level. To achieve the desired height and shape, additional constructs in the form of splines were required (combining two points with a spline - a straight line) to further fix the slope of the parapet points. It is important to understand the effect of reference points as in most cases they are critical in the creation of reference lines tied to the geometry of another object.
When Dynamo is used during the design process (which makes it possible to generate the building volume at the preliminary design stage or create a complex parametric shell with adaptive inserts), this, of course, simplifies it and makes it more automated, but this is only one of the application options. To make full use of all mass advantages, it is necessary to utilize masses in parallel with the detailed documentation stage. We will consider an example of such an application below.

Stairs + masses. It is actually an unusual application of the tool, which, however, plays a significant role in the development of detailed documentation for the project. Let us consider the following task: it is needed to read the stairs finishing, and, if the finishing consists of several layers, display the "pie" graphics in section views (Figure 12). In order to do that, it is necessary to use a stock Stairs object, based on which a form following the form of the stairs (Figure 14) is created using a script (Figure 13). Based on the form, the Roof by Face tool is used, which reproduces the multi-layer "pie" of the structure. Due to this method, the finishing of stairs does not require high labor intensity.
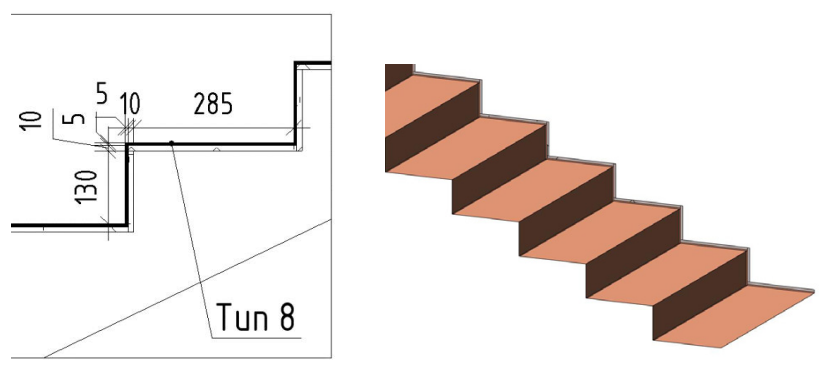

Figure 12. Stairs finishing "pie"

It should be added that the end parts of the finishing are modeled with fascias, and then, upon changes in the width of the roof by face, the fascia adjusts according to its host element. Calculations are carried out through assemblies, fascias form particular parts, and, eventually, material takeoff schedules are generated. It is possible to model forms every time when a host element changes its geometry, in which case the new form completely replaces the old one as it has the following structure in its name: "Selection category_ID".

The script is quite easy to execute. Depending on the complexity of tasks, its transformations can create a required interface for work with elements. It is possible to add pop-up windows in the main body of the script, using additional Dynamo packages, transform it in a way so that it could work with multiple objects simultaneously, insert initial data on the geometry offset, etc. The basic logic will be uniform and, depending on the complexity of elements' geometry, it will be transformed in the python script body code. 

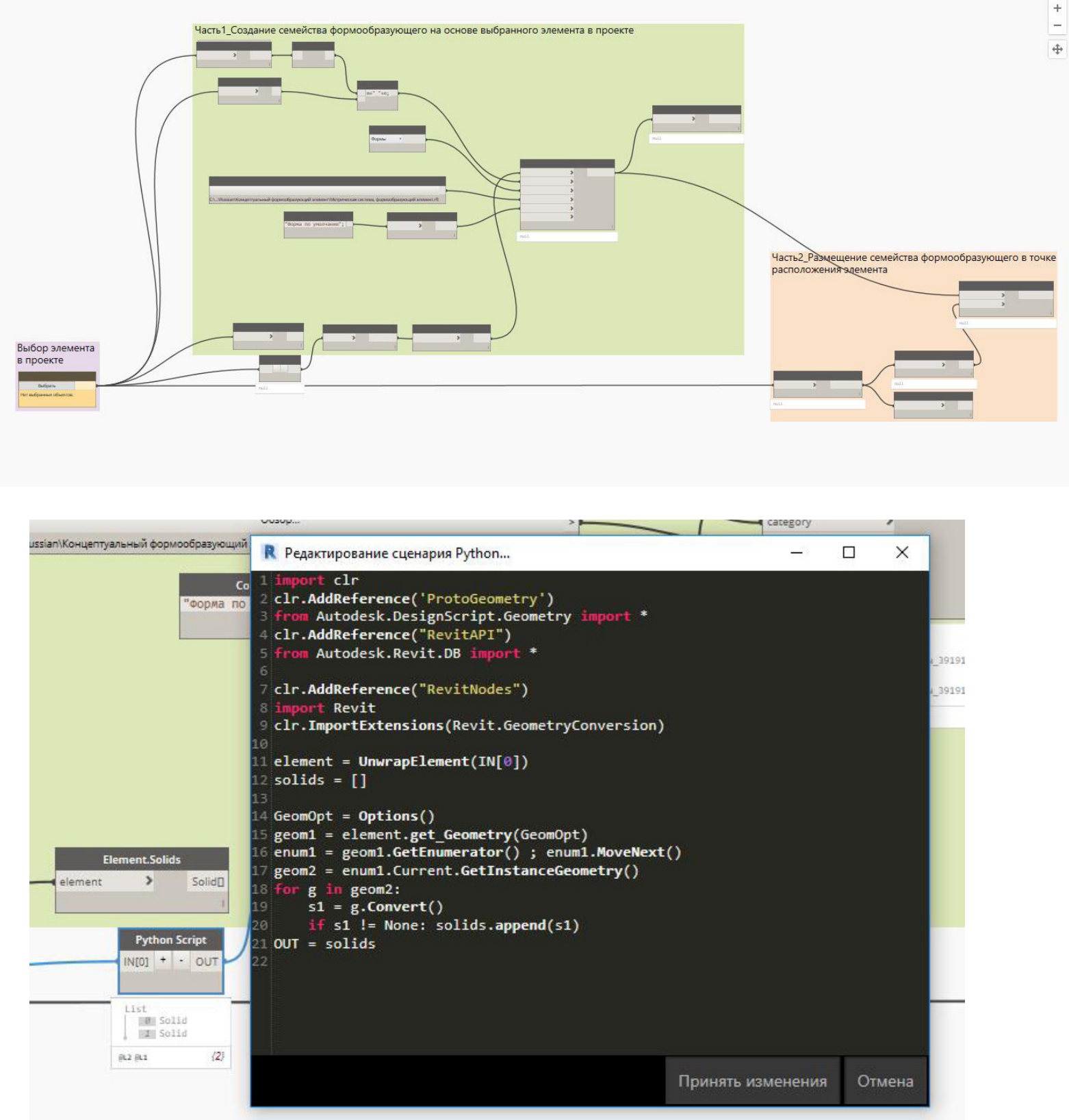

Figure 13. Dynamo script + Python

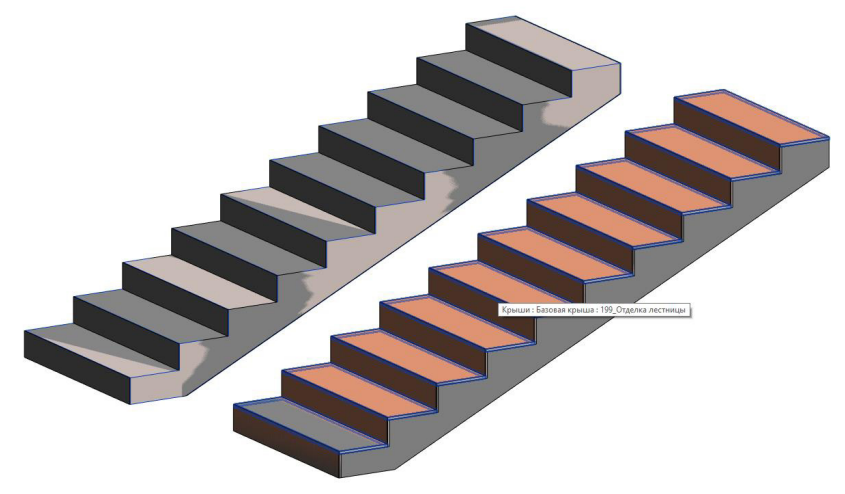

Figure 14. On the left: system stairs with a superimposed form, on the right: form + Roof by Face 
Facades and their metal subsystems. There can be a wall in the initial data, connected to a sloped floor, on the basis of which a form element will be created, and then an element of the facade subsystem will be constructed (Figure 15).

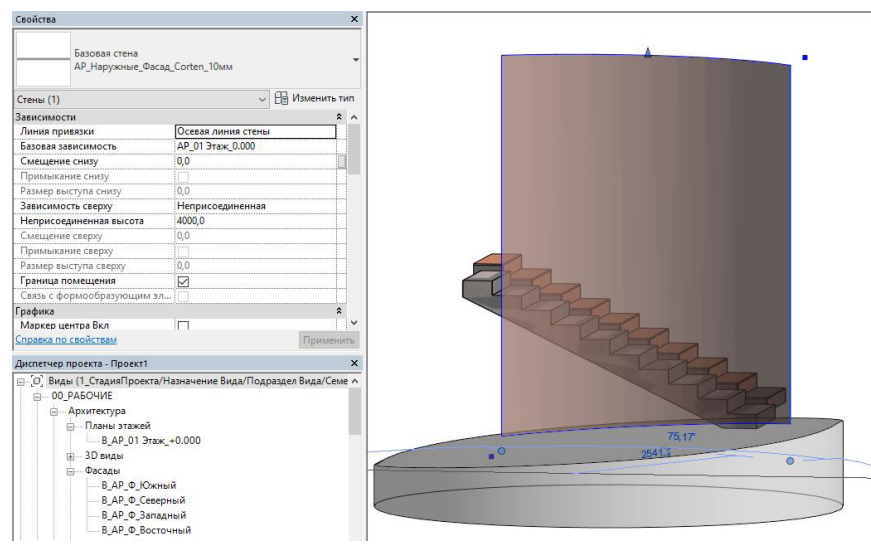

Figure 15. Initial geometry

After the script launch, a form repeating the geometry of the wall is superimposed on that wall. Then a customized curtain system with profiles of metal guides is built covering the form (Figure 16).
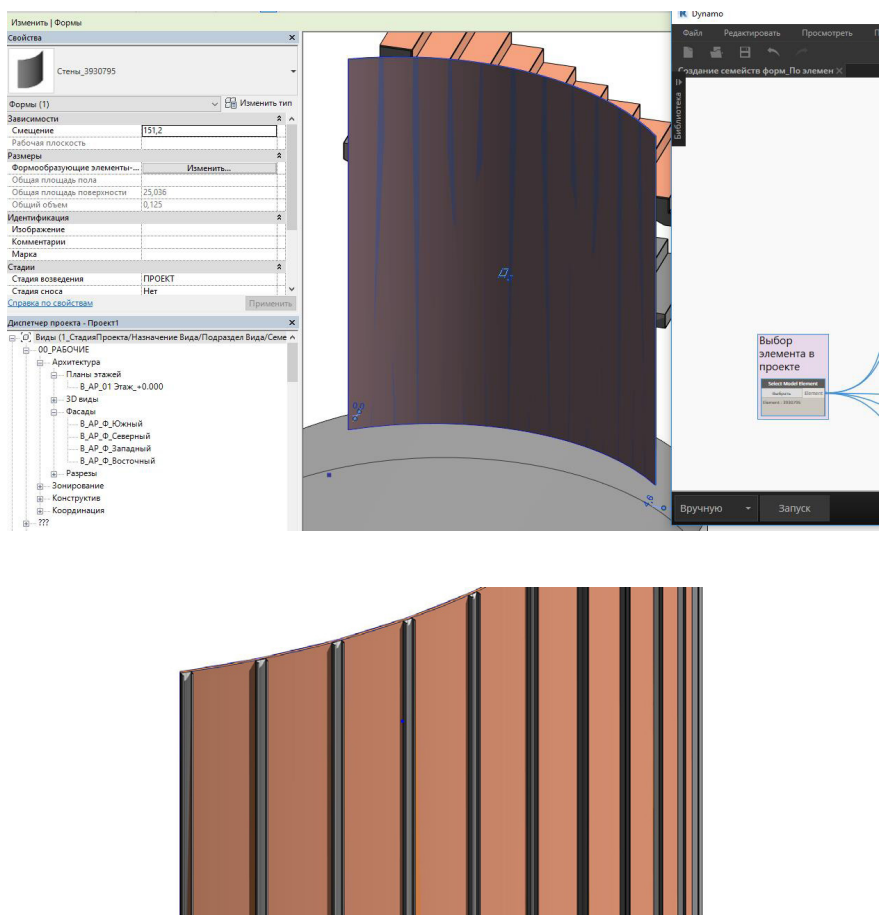

Figure 16. Form repeating the geometry of the wall. Curtain system created on its basis

Thus, the combination of these tools will help to avoid some problems associated with the development of detailed documentation. It should also be remembered that Dynamo reads the geometry of elements in different ways, depending on the complexity of the selection geometry. Depending on the complexity of the source element available in the project, either standard geometry extraction nodes or python script are used. For the convenience of writing the latter, it is better to use NotePad++ and PyCharm (Foord, Muirhead, 2009; Van Rossum, Drake, 2001; Vysotskiy Consulting, 2019).

Only the host is subject to manual modeling, therefore, the speed of introducing changes is the most important advantage of such binding since continuous change and transformation represent object constants (Hardin, McCool, 2015).

This method makes the process of introducing changes (when designing forms of curved geometry) easier and faster. In fact, only the initial mass is subject to alteration, while the rest undergo changes according to the presented logic.

Railings. There is wide variability in the creation of railings, following the same principle of action as in case of the form + curtain system binding (Figure 17). The process of calculating balusters, rails, and guides is significantly simplified as all elements of such railings are curtain wall mullions. Of course, it all depends on the structural complexity of railings, but, as experience shows, work with curtain grids and imposts is much easier in terms of the process of introducing changes to the railing structure and in the way of calculating their elements. Usually, to calculate elements of railings created using a curtain system, assemblies are used. When calculating rails/balusters, to distinguish them from each other, it is possible to use calculation formulae depending, for example, on the impost length.

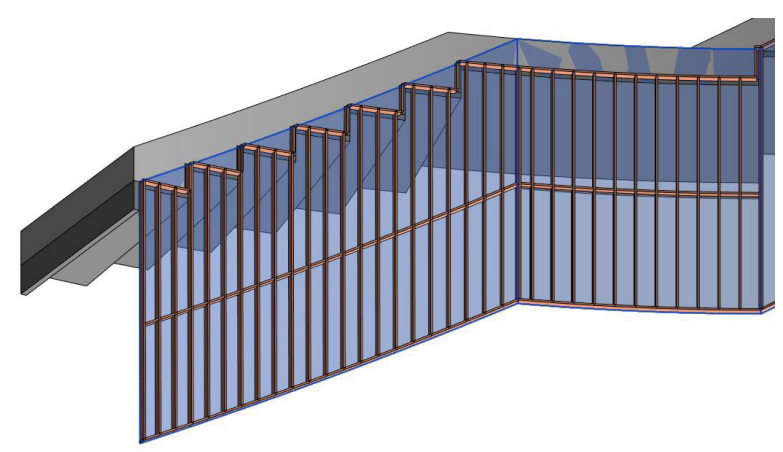

Figure 17. Curtain system (railings) + mass

\section{Conclusions}

When designing objects of complex geometric forms, the use of such Autodesk Revit tools as masses, Model In-Place elements (categories replacing system families), as well as the interaction between toolkit products and objects of process automation (using Dynamo) create a new paradigm of modeling non-standard objects. Such approach combines correct geometry and information content. Clear formation of the project structure, logic of modeling with regard to each aspect of the total geometry volume and use of automation methods ensure that geometrically complex objects are designed without losing additional time to edit and make changes, and the total timing budget to model volumes of complex forms is optimized. 


\section{References}

Foord, M.J., Muirhead, C. (2009). Iron Python in Action. New York: Manning Publications Company, 480 p.

Garber, R. (2014). BIM Design. Information Modelling Today. New York: John Wiley \& Sons, 248 p.

Hardin, B., McCool, D. (2015). BIM and Construction Management: Proven Tools, Methods, and Workflows. New York: John Wiley \& Sons, $416 p$

Kensek, K., Noble, D. (2014). Building Information Modeling. 12.4.4 BIM + Knowledge. New York: John Wiley \& Sons, 432 p.

Krygiel, E., Nies, B., McDowell, S. (2008). Green BIM: Successful Sustainable Design with Building Information Modeling. New York: John Wiley \& Sons, 268 p.

Lantsov, A.L. (2014). Autodesk Revit 2015. Computer-aided building design. Moscow: RIOR, 664 p.

Mogilina, V.S. (2018). Possibilities of automating repetitive tasks in Dynamo Revit during Green BIM project design. In: Vityuk Ye.Yu., Zakharova G.B., Semyonov A.A., Titov S.S. (eds.) New Information Technologies in Architecture and Civil Engineering: Proceedings of the Russian Scientific Conference with International Participation. Yekaterinburg: Ural State University of Architecture and Art, p. 34.

Oolacay, Z.H. (2015). Application of technology BIM in building design. In: Sandan A.S. (ed.) Relevant problems of implementing energy saving and energy efficient technologies in the design, construction and engineering system of municipal engineering: II international research-to-practice conference. Kyzyl: Tuvan State University, pp. 85-89.

Poddorogina, Y.A. (2018). Development of construction projects in Revit using the Dynamo plugin. In: Vityuk Ye.Yu., Zakharova G.B., Semyonov A.A., Titov S.S. (eds.) New Information Technologies in Architecture and Civil Engineering: Proceedings of the Russian Scientific Conference with International Participation. Yekaterinburg: Ural State University of Architecture and Art, p. 41.

Read, P., Krygiel, E., Vandezande J. (2011). Autodesk Revit Architecture 2012 Essentials. New York: John Wiley \& Sons, 1152 p.

Shariq, A. (2010). Analysis of procedures and workflow for conducting energy analysis using Autodesk Revit, GBXML and Trace 700. In: Fourth National Conference of IBPSA-USA New York City, New York. pp. 56-57.

The American Institute of Architects, etc. (2019). Level of Development (LOD) Specification Part I \& Commentary for Building Information Models and Data. US: BimForum, $256 \mathrm{p.}$

Vandezande, J., Krygiel, E., Read, P. (2013). Autodesk@ Revit@ Architecture 2013-2014. Official Training Guide. Translated by Talapov V.V. Moscow: DMK Press, 330 p.

Van Rossum, G., Drake, F.L. (2001). Python programming language. Available at: http://proga-school.narod.ru/My_Python/ book-ods.pdf (accessed on: 15.06.2019)

Vysotskiy Consulting (2019). Dynamo: routine automation and additional functions for Revit. Available at: http://bim.vc/dynamo/ (accessed on: 15.10.2019) 


\title{
«REVIT DYNAMO: ПРОЕКТИРОВАНИЕ ОБЪЕКТОВ СЛОЖНЫХ ФОРМ. ОСОБЕННОСТИ ИНСТРУМЕНТАРИЯ И АВТОМАТИЗАЦИИ ПРОЦЕССОВ॥
}

\author{
Дарья Львовна Шишина', Филипп Вячеславович Сергеев² \\ 1,2ООО «ИНПИ» \\ ул. Ямского поля 3-я, д. 2, корп. 1, г. Москва, Россия \\ ${ }^{2}$ Автор ответственный за переписку: sergeev@i-npi.ru
}

\section{Аннотация}

Введение: Проектирование объектов сложных фформ (непрямолинейных, округлых, динамичных в своей геометрии) на сегодняшний день вызывает сложности при построении геометрии и выпуске документации различных стадий проекта. В работе представлены зарекомендовавшие себя подходы в моделировании сложных форм. Подразумеваются формы, представляющие собой плоскости с изгибами в 3 направлениях, выполнить которые необходимо в соответствии с правилами графического отображения чертежей. Методы: Рассматривается инструментарий программы Autodesk Revit (формообразующие, модель в контексте) в совокупности с дополнительным скриптом, созданным с помощью дополнения для визуального программирования - Dуnато. Сформулированы подходы к работе со сложной геометрией в Revit, позволяющие корректно смоделировать объекты сложных фрорм. Приведены примеры использования стандартных инструментов программы в нетипичной для них логике применения. Так как стандартные инструменты имеют ограниченный функционал, показан способ использования скрипта на базе Dупато, который автоматизирует и ускоряет процесс создания геометрических форм. Результаты и обсуждение: Произведен процесс оптимизации работы с нестандартными экземплярами геометрии проекта, а также на основе наработанных материалов сформулирована дальнейшая парадигма проектирования нестандартных объектов строительства.

\section{Ключевые слова}

Формообразующие, модель в контексте, автоматизация, сложность форм, адаптивность 